\title{
The Proportion of Gaming Revenue Derived from Problem Gamblers: Examining the Issues in a Canadian Context
}

\author{
Robert J. Williams* \\ University of Lethbridge

\section{Robert T. Wood} \\ University of Lethbridge
}

The legitimacy of government-sponsored gambling and its continued expansion depends in part on the impact that gambling has on society and the extent to which gambling revenue is derived from vulnerable individuals. The purpose of the present article is to try to establish a valid estimate of the proportion of gaming revenue derived from problem gamblers in Canada. Using recent secondary data collected in eight Canadian provinces, we estimate this proportion to be $23.1 \%$, compared to a problem gambling prevalence rate of $4.2 \%$. This estimate must be seen as tentative, however, as self-reported expenditures are 2.1 times higher than actual provincial gaming revenues.

Gambling is an important and expanding economic growth industry in Canada. Net revenue from government-run lotteries, video lottery terminals, and casinos rose from \$2.7 billion in 1992 to \$11.3 billion in 2002 (Statistics Canada, 2003). Gambling is also a socially acceptable activity, with the large majority of Canadians reporting that they gamble at least occasionally (Azmier, 2000; Statistics Canada, 2003). It is not surprising to observe such high proportions of gamblers in light of the many gambling opportunities available to Canadians. Lotteries, instant-win tickets, sports betting (Sports Select), electronic gaming machines

\footnotetext{
* Correspondence concerning this article should be addressed to Robert Williams, School of Health Sciences, University of Lethbridge, Lethbridge, Alberta T1K3M4 [e-mail: Robert.williams@uleth.ca].

We wish to thank Nadine Nowatzki for her valuable assistance in collecting and analyzing the data for the Results Section. We also wish to thank Tracy Schrans from Focal Research for kindly providing the recent data from the New Brunswick prevalence study and Donna Klingspohn for providing some of the data for the British Columbia study.
} 
(video lottery terminals or slot machines), bingo, and horse racing are available in every province. In addition, all provinces except New Brunswick, Newfoundland, and Prince Edward Island have permanent casinos (Azmier, 2001).

Government's role in gambling varies from country to country. In jurisdictions such as the United States, the government primarily serves as a regulator and receives revenues mostly through taxation of private operators. Canada has much more government involvement than most jurisdictions. Here, provincial governments not only serve as regulators, but are often involved in the actual ownership and operation of gambling and are the primary recipients of revenue from these operations (Azmier, 2001).

Direct government involvement in gambling is a contentious issue, with some people arguing this enterprise is incompatible with serving the best interests of the people. It is clear that there are many positive social and economic benefits to government-sponsored gambling. In addition to being a desirable source of entertainment, it also provides employment for many people and injects large sums of much needed revenue into government and charity coffers (Azmier, Kelley, \& Todosichuk, 2001; Wynne \& Anielski, 2000). Most of this revenue is then redirected to fund important public services, programs, and facilities (Azmier et al., 2001).

However, not all Canadians benefit from gambling. On the contrary, a minority of Canadians suffer from very serious gambling problems. Nine recent provincial prevalence studies have found rates of problem gambling ranging from $3.1 \%$ to $5.9 \%$ of the adult population, with an average of $4.2 \%$ (Addictions Foundation of Manitoba, 2002; Baseline Marketing Research, 1996; Doiron \& Nicki, 1999; Ipsos-Reid \& Gemini Research, 2003; Ladouceur, Jacques, Ferland, \& Giroux, 1999; New Brunswick Department of Health \& Wellness \& Focal Research, 2001; Smith \& Wynne, 2002; Wiebe, Single, \& Falkowski-Ham, 2001; Wynne, 2002). For these people, government-sponsored gambling results in financial, psychological, and inter-personal ruin. Moreover, the problems associated with pathological gambling, such as marital breakdown, unemployment, mental illness, and crime, all place a significant strain on Canada's social infrastructure.

Many governments justify their involvement in gambling by their belief that the social and economic benefits outweigh the negative effects. The argument can also be made that the situation is analogous to alcohol where the government is mandated with regulating and managing a product that is supported by the majority of the population despite having adverse effects for a minority. However, there are a couple of problems with these arguments. First, it is not clear that the benefits of gambling outweigh the negative effects in places that do not attract a substantial portion of their patrons from other jurisdictions (Gerstein et al., 1999; Productivity Commission, 1999; Wynne \& Anielski, 2000). Secondly, unlike alcohol, most governments have yet to develop or implement effective policies to minimize the harm caused by gambling (Blaszczynski, 2003; Nowatzki \& Williams, 2002; Quinn, 2001). 
Of final note, and most relevant to the present article, there has been no thorough or conclusive determination of what proportion of government gambling revenue derives from problem gamblers. Even if effective prevention policies were in place and the benefits of gambling did outweigh the negative effects, important consideration has to be given to the source of the money. It seems doubtful that government alcohol revenue derives primarily from alcoholics due to the fairly low cost of alcohol and limits on how much alcoholics can consume (although we are unaware of any studies investigating this issue). However, this may not be the case with problem gamblers, many of whom lose their homes and entire life savings in relatively short periods of time (Gerstein et al., 1999; National Research Council, 1999; Productivity Commission, 1999). To our minds, the very legitimacy of government-sponsored gambling hinges on the assumption that a large portion of the revenue does not come from an addicted and vulnerable segment of the population. ${ }^{1}$

Australia, New Zealand, and the United States have examined what proportion of their revenue derives from problem gamblers as part of comprehensive investigations into the general impact of gambling in their respective countries. Lesieur (1998) also examined this issue for three Canadian provinces and four U.S. states. The results of these investigations are reported in Table 1. As can be seen, all four of these studies found that the estimated proportion of gaming revenue derived from problem gamblers was far in excess of the estimated proportion of

Table 1. Jurisdictional Estimates of Proportion of Revenue from Problem Gamblers

\begin{tabular}{lcc}
\hline Jurisdiction & $\begin{array}{c}\text { Prevalence of Past } \\
\text { Year Problem } \\
\text { Gamblers }\end{array}$ & $\begin{array}{c}\text { Proportion of Revenue } \\
\text { from Problem Gamblers }\end{array}$ \\
\hline $\begin{array}{l}\text { Australia } \\
\text { (Productivity Commission, 1999) }\end{array}$ & $\begin{array}{c}2.1 \% \text {; SOGS }(5+)^{\mathrm{a}} \\
(4.9 \% ; \text { SOGS 3+) }\end{array}$ & $33 \%$ \\
$\begin{array}{l}4 \text { U.S. States and 3 Canadian Provinces } \\
\text { (Lesieur, 1998) }\end{array}$ & N/A; SOGS $(3+)^{\mathrm{b}}$ & $\begin{array}{c}30 \% \\
\text { New Zealand } \\
\text { (Abbott and Volberg, 2000) }\end{array}$ \\
$\begin{array}{l}\text { United States } \\
\text { (Gerstein et al., 1999) }\end{array}$ & $1.3 \%$; SOGS $(3+)^{\mathrm{c}}$ & $19 \%$ \\
\hline
\end{tabular}

${ }^{\text {a}}$ Problem gambling defined as having a score on the South Oaks Gambling Screen of 5 or higher in the past year. Prevalence rate is $4.9 \%$ if use a score of 3 or higher.

${ }^{\mathrm{b}}$ Problem gambling defined as having a score on the South Oaks Gambling Screen of 3 or higher in the past year.

${ }^{\mathrm{c}}$ Problem gambling defined as having a score on the South Oaks Gambling Screen of 3 or more in the past 6 months.

${ }^{\mathrm{d}}$ Problem gambling defined as meeting 3 or more of the DSM-IV criteria for pathological gambling in the past year.

${ }^{1}$ We are unaware of any government statement on this issue. However, it is the stated position of the American Gaming Association that only a very small proportion of gaming revenue in the United States comes from problem gamblers. 
problem gamblers in the population, ranging from $15 \%$ in the United States to $33 \%$ in Australia.

However, these results are far from conclusive, as reported expenditures did not match actual gaming revenues collected by the industry and government in any of these studies. The Australian and New Zealand studies found total self-reported expenditures to be between one-half to three-fourth of the actual revenues (Abbott \& Volberg, 2000; Productivity Commission, 1999). In the U.S. study, gamblers reported being ahead by $\$ 3$ billion at the casinos in the past year instead of having left more than $\$ 20$ billion, the revenues reported by the casino industry. Gamblers also reported being ahead by $\$ 2$ billion at the racetrack and $\$ 4$ billion in private gaming. Only when it came to lotteries did they admit to a loss of $\$ 5$ billion (Gerstein et al., 1999).

The purpose of the present article is to try to establish a valid estimate of the proportion of gaming revenue derived from problem gamblers in Canada. Using recent secondary data collected in eight Canadian provinces, we calculate a comparative inter-provincial estimate, as well as a tentative overall national estimate. Building upon trends and issues emerging from our data analysis, we then propose and outline improved methodology for future investigation of this issue that will produce more valid estimates in the Canadian context, as well as in other contexts internationally. We conclude the article with a discussion of the policy implications that our study holds for government-sponsored gambling in Canada.

\section{Method}

In order to estimate the proportion of revenue derived from problem gamblers in each province, we followed a sequence of methodological steps. We first began by obtaining the most recent prevalence estimates of adult problem gamblers for each province where this information was available. Since 1996 all provinces except for Newfoundland have conducted province-wide prevalence surveys of problem gambling using either the Canadian Problem Gambling Index (CPGI) (Ferris and Wynne, 2001) or the South Oaks Gambling Screen (SOGS) (Lesieur \& Blume, 1987, 1993). These instruments define problem gambling as gambling that is associated with some significant adverse consequences for the individual or people in his/her immediate social network in the past year. Problem gambling also includes "pathological gambling," a more extreme form where the person not only experiences persistent and recurrent problems, but also shows signs of being preoccupied with gambling, dependent on it (e.g., withdrawal symptoms if not engaged in), and some inability to resist engaging in it (APA, 1994). Scores of 3 or 4 on the SOGS have most often been considered "problem gambling" and scores of 5 or higher are considered "probable pathological gambling." On the CPGI, scores of 3 to 7 indicate "moderate risk gambling" (equivalent to problem gambling) and 
scores of 8 and higher indicate "severe problem gambling" (roughly equivalent to pathological gambling).

Using these provincial prevalence rates, the actual number of adult $(18+)$ problem gamblers and adult nonproblem gamblers, in each province, was estimated using population data from Statistics Canada for that particular time period.

Of the nine provincial prevalence studies, eight of them (not Quebec) asked people about their "typical monthly spending" on specific types of gambling. For problem gamblers in each province, we added up their average reported expenditures on all games contributing to provincial government, Native, charity, or horseracing association revenue (i.e., not out-of-province gambling, internet gambling, gambling with friends, betting with a bookie, or stock market investments). We multiplied these monthly expenditure totals by 12 to obtain an estimate of their average yearly gambling expenditure. We then multiplied this amount by the estimated number of problem gamblers in the province. The same procedure was used for the nonproblem gamblers (i.e., their average monthly expenditures multiplied by 12 and then by the estimated number of nonproblem gamblers in the province). The total reported expenditures of problem gamblers was added to the total reported expenditures of nonproblem gamblers. Finally, we determined what percentage of the combined amount was accounted for by the total expenditures of the problem gamblers.

In order to check the validity of our findings, we compared our estimates of total reported gambling expenditures to total provincial government, Native, charity, and horseracing association gross gaming revenue reported in the time period the prevalence study was done.

\section{Results}

Referring to the results in Table 2, it is apparent that significant inter-provincial variation exists concerning both problem gambling prevalence rates, the proportion of gaming revenue that problem gamblers generate, and the ratio of reported expenditures to actual revenue. Turning first to the prevalence of problem gambling in the Canadian provinces, we see that rates range from a low of $3.1 \%$ in Prince Edward Island to $5.9 \%$ in Saskatchewan, with an average of $4.2 \%$. While there is reason to believe that actual inter-provincial differences in problem gambling prevalence do exist (due to different governmental gambling policies as well as differences in gambling opportunities for citizens), some of this variability is due to differences in how these figures were calculated in each province.

One important source of variability is the use of the SOGS in some provinces and the CPGI in others. The SOGS was designed principally for use in clinical settings rather than epidemiological work, and is known to have a significant false-positive bias relative to other instruments or clinical interviews (Abbott \& Volberg, 1996; Ladouceur et al., 2000; Ferris \& Wynne, 2001; Shaffer, Hall, \& 
Table 2. Estimated Proportion of Revenue from Problem Gamblers in each Canadian Province

\begin{tabular}{lcccc}
\hline & $\begin{array}{c}\text { Prevalence of } \\
\text { Past Year } \\
\text { Problem } \\
\text { Gamblers }\end{array}$ & $\begin{array}{c}\text { Date of } \\
\text { Prevalence } \\
\text { Survey }\end{array}$ & $\begin{array}{c}\text { Proportion of } \\
\text { Reported Past Year } \\
\text { Expenditures } \\
\text { Accounted for by } \\
\text { Problem Gamblers }\end{array}$ & $\begin{array}{c}\text { Ratio of Reported } \\
\text { Expenditures to } \\
\text { Actual Provincial } \\
\text { Gaming Revenues }^{\text {brovince }}\end{array}$ \\
\hline British Columbia & $\begin{array}{c}4.6 \% \text { CPGI (3+) } \\
\text { Alberta }\end{array}$ & 2002 & $26.2 \%^{\mathrm{c}}$ & $1.1(.65)$ \\
Saskatchewan & $5.2 \%$ CPGI (3+) & 2001 & $30.6 \%$ & $1.72(1.09)$ \\
Manitoba & $5.9 \%$ CPGI (3+) & 2001 & $25.2 \%$ & $1.72(1.27)$ \\
Ontario & $3.4 \%$ CPGI (3+) & 2001 & $18.9 \%^{\mathrm{c}}$ & $(1.23)$ \\
Quebec & $3.8 \%$ CPGI (3+) & 2001 & $37.5 \%^{\mathrm{c}}$ & $1.31(.94)^{\mathrm{e}}$ \\
New Brunswick & $4.5 \%$ SOGS (3+) & 1996 & NA & NA \\
Nova Scotia & $3.2 \%$ CPGI (3+) & 2001 & $32.6 \%$ & $.77(.59)$ \\
P.E.I. & $3.9 \%$ SOGS (3+) & 1996 & $7.3 \%$ & $4.07(3.47)$ \\
Newfoundland & $3.1 \%$ SOGS (3+) & 1999 & $6.3 \%$ & $4.19(2.87)$ \\
NWT, YK \& Nunavut & NA & NA & NA & NA \\
Average & NA & NA & NA & NA \\
\hline
\end{tabular}

${ }^{a}$ Based on total reported annual expenditure of gamblers on games contributing to provincial government, Native, charity, or horseracing association revenue (i.e., not internet gambling; out-of-province gambling; betting with friends; stock market investments; sports betting pools; betting with bookie).

${ }^{\mathrm{b}}$ Total provincial government, Native, charity, and horseracing association gross gaming revenue (after prizes and winnings) reported in the time period the prevalence study was done. Does not include licensing fees and does not include nongaming revenue (e.g., food, alcohol). Numbers in brackets are the ratios calculated from revenues before prizes are paid out for lottery and charity gaming.

${ }^{c}$ This figure is for all types of gambling as it was not possible to separate out expenditures just on games contributing to provincial government, Native, charity, or horseracing association revenue.

${ }^{\mathrm{d}}$ The average expenditure of the lifetime problem or pathological gamblers was used for this calculation, as expenditure of past year problem gamblers was not available.

${ }^{\mathrm{e}} \mathrm{A}$ significant proportion of Ontario gaming revenue derives from out-of-province residents. According to the Ontario Casino Corporation, $80 \%$ of the roughly 60,000 daily visitors to the four major Ontario casinos are American.

Vander Bilt, 1997). In contrast, the CPGI was designed to assess gambling behavior in general populations and is geared toward the gambling opportunities available in the Canadian context (Ferris \& Wynne, 2001). A related confound is that all studies using the CPGI were conducted in 2001 versus 1996 for two of the three SOGS studies, an important consideration in light of the changes that have occurred in gambling availability and participation since the mid 1990s. Other problems that limit comparisons between the provinces include the fact that each survey used different training and supervision protocols for the interviewers, and each had widely different overall response rates. Of final note, the confidence intervals around each prevalence rate is fairly large, as all of these studies are calculating rates on the basis of only 25 to 190 problem gamblers (average of 84).

These same provisos apply to the inter-provincial variability seen in the proportion of revenue accounted for by problem gamblers. Referring to Table 2, we see that the proportion of reported past year expenditures accounted for by problem gamblers ranges from $6.3 \%$ in Prince Edward Island to $37.5 \%$ in Ontario. Again, while there may well be real differences in this proportion between provinces, it 
must be assumed that measurement differences account some of this variation. In addition to the problems noted above, one of these proportions (NS) was calculated on the basis of the past year reported expenditure of lifetime (rather than past year) problem gamblers and some of the proportions (BC, MB, ONT) were calculated for all types of gambling (as opposed to just games contributing to provincial government, Native, charity, or horseracing association revenue).

It is our belief that the most meaningful figure is the proportion of revenue derived from problem gamblers averaged across all jurisdictions: $23.1 \%$. If our observed average prevalence rate of $4.2 \%$ is indeed correct, then problem gamblers report a proportion of expenditure that is more than five times their proportion among the Canadian population.

If gamblers' reported expenditures equal the actual amount of net gaming revenue in each jurisdiction (in which case we would observe ratios of 1.0 in the final column of Table 2), then we could have some assurance that the observed proportions of total expenditures reported by problem gamblers is a true reflection of the actual proportion of gaming revenue generated by problem gamblers. As the reader will notice in the final column of Table 2, however, most observed ratios are not close to 1.0. Instead, in almost all cases the reported expenditures of gamblers exceeded the actual provincial government, Native, charity, and horseracing association gaming revenue (after prizes paid) in that time period. The ratio of reported expenditures to actual revenue varied from a low of .77 in New Brunswick to a high of 4.2 in Prince Edward Island. The average ratio was 2.1.

It is quite possible that when people are asked about their "typical monthly spending" on various forms of gambling that instead of reporting their net win or loss, they are actually reporting their "outlay," or how much total money they have put toward gambling in that time period. ${ }^{2}$ Thus, the numbers in brackets are the calculated ratios of self-reported expenditure to gross revenues, in other words, revenue before prizes are paid out for lottery and charity gaming. However, as can be seen, although some individual ratios are much closer to 1.0, overall self-reported expenditures still exceed gross revenues by an average ratio of 1.5 .

\section{Discussion}

While the figures reported here are not necessarily conclusive, they do at least offer support for the proposition that problem gamblers generate a disproportionate share of provincial gaming revenue. The degree to which $23.1 \%$ is

\footnotetext{
${ }^{2}$ This would seem especially plausible for types of gambling where the outcome is not immediately determined (e.g., lottery purchases, some types of sports betting) and/or where there is a regularized pattern of spending (e.g., always spending a fixed amount per session or per week). It seems less plausible for continuous forms of gambling where the outcome is immediately known (slot machines, video lottery terminals, instant-win tickets, casino table games, horse races) and when gambling involvement is irregular.
} 
"excessive," is a matter for debate. What is less debatable is that if provincial governments are going to make gambling available to their citizens, then concerted efforts are needed to prevent problem gambling, to effectively treat gambling addiction, and to minimize the amount of gambling revenue that comes from problem gamblers.

In this regard, further efforts are needed. There are several unused policy options provincial governments have available to accomplish some of these goals. These include the banning of automatic teller machines from gaming venues, the elimination of bill takers on electronic gaming machines, smoking bans (most problem gamblers are smokers), restriction of electronic gaming machines to gaming venues, and the implementation of effective casino self-exclusion programs (Blaszczynski, 2003; Nowatzki \& Williams, 2002; Quinn, 2001). It is also important to note that the percentage of gross gaming revenue that provincial governments redirect to prevention and treatment of problem gambling $(.3-1.2 \%$; Azmier, 2001) is a very small fraction of the gaming revenues generated by problem gamblers. Although expressed need for treatment is also important in determining resource allocation, expressed need is typically influenced by treatment quality and availability. On the basis of our findings, it is our contention that the amount of money devoted to prevention and treatment of problem gambling (and research on how to best accomplish this) needs to be increased so as to be more proportionate to the amount of gaming revenue this segment of gamblers generates.

It is interesting to note that $23.1 \%$ is a lower proportion of revenue from problem gamblers than estimated for Australia (33\%), but higher than estimated for New Zealand (19\%) and the United States (15\%). Whether this is a real difference or artifactual is unclear. However, the fact that the proportion of revenue from problem gamblers bears a strong linear relationship to the respective rates of problem gambling in each of these countries lends support to the contention that these differences are real.

It must be re-emphasized that the calculated proportion of revenue derived from problem gamblers $(23.1 \%)$ is very tentative in light of the significant overreporting of expenditures relative to actual revenues. This figure would only be accurate if the degree of over-reporting is the same for all types of gamblers and all types of gambling, an unproven assumption. Clearly, more research is needed to get a more precise and reliable estimate of what this actual proportion is. To be fair, the studies reviewed in this article were not designed with the primary goal of determining this proportion, and so we are not advocating a negative critique of these important studies and the valuable contributions they have made to the broader body of knowledge about problem gambling issues. Nonetheless, if researchers wish to gain a clear understanding of the proportion of government gaming revenues generated by problem gamblers, then additional research is needed. To this end, we turn now to a series of informed recommendations for how future studies should proceed. 


\section{Recommendations for Future Studies}

\section{Clarify the Meaning of Expenditure Questions}

In the absence of objective data on individual gambling expenditures, the only strategy is to improve the validity of self-report. ${ }^{3}$ One way of doing this is by clarifying the meaning of expenditure questions. Virtually all prior studies have obtained self-reported expenditures as part of a telephone survey investigating the prevalence of problem gambling in their particular state or province. Certain questions in these surveys have asked people how much they spend on a specific gambling activity in a "typical" month. Figures for each activity are then added up to arrive at a typical monthly expenditure. The usual intent of these questions is to obtain an estimate of the respondent's average net monthly gambling loss or win (i.e., the amount of money they have at the end of the month compared to the beginning of the month). However, even among educated medical students, only $32 \%$ to $64 \%$ interpret "how much do you spend gambling?" to mean net expenditure (Blaszczynski, Dumlao, \& Lange, 1997). Many interpret it as initial outlay or total outlay (initial outlay + reinvestment of winnings), as we speculate is the case for the Canadian studies analyzed earlier in this article. Blaszcynski et al. (1997) also found that some people include travel and meal costs when calculating gambling expenditures. Also problematic, it is unknown whether people interpret "typical" as mean, median, or modal expenditures. It is quite plausible that people believe "typical" to mean their usual (modal) expenditure, rather than their statistical average that takes into account occasional large losses.

\section{Avoid Biased Wording of Questions}

How a question is worded strongly influences respondents' replies (Schwarz, 1999). Almost all studies of problem gambling expenditures and revenues have asked people how much they "spent" in the past month, which could bias them toward reporting losses rather than wins. Although losses are much more common than wins, there are a few gamblers who do come out ahead (e.g., infrequent gamblers, lottery winners, professional sports handicappers, professional poker players). Moreover, if gambling activities also include the stock market, as they do in several of these surveys, then many more people are "winners." As evidence of the importance of how the question is worded, the National Opinion Research Center study (Gerstein et al., 1999) did ask respondents whether they had "come

\footnotetext{
${ }^{3}$ Detailed records of gambling expenditure are kept for "high rollers" in a few jurisdictions such as Las Vegas, but not for other people. In many places in the United States (but only recently introduced in a few places in Canada), people can obtain a "player card" from the casino, which will keep track of that person's spending at that venue (so as to obtain complementary food, etc.). However, only a portion of players access this option and it only tracks play at that casino.
} 
out ahead or behind on your gambling," with the choices being "ahead, behind, or broke even. With this wording, a majority of people reported winning rather than losing money in the past year. Thus, it is likely that people interpreted "come out behind" as having negative connotations, which in turn biased their responses. Research suggests that questions on gambling expenditures are highly subject to social desirability, with people tending to exaggerate their wins and losses to convey the impression they are high rollers (Ruehlman, 2001).

\section{Account for the Fallibility of Memory}

Even if people correctly interpret question wording, and even if question wording does not bias them, their ability to accurately provide average net monthly win/loss is doubtful. This statistical calculation is difficult to make in the few seconds that most researcher-administered surveys provide. The fact is that these figures are usually not available and the person is just relying on their memory of these expenditures to make these calculations. Even if people are encoding their daily/weekly/monthly expenditures in terms of net win/loss, memories have differing valence, making them more or less available for retrieval (Tourangeau, 2000). Indeed, selective memory is a characteristic and well-documented feature of problem gambling (Toneatto, 1999; Toneatto, Blitz-Miller, Calderwood, Dragonetti, \& Tsanos, 1997).

Thus, researchers of problem gambling revenues can bolster the validity of their findings by either asking about shorter time frames or using Time-Line Follow-Back procedures that guide the person through a retrospective account of their expenditures, encouraging them to think of important dates or events as anchors (Sobell \& Sobell, 1996).

\section{Utilize Prospective Diary Methods}

Prospective diaries involve participants recording relevant behaviors or experiences in a type of logbook or diary, on a daily basis, for a certain period of time. Prior research provides substantial support for the contention that prospective diaries will almost certainly provide the most valid data when measuring socially undesirable behavior, mainly due to the advantage of not having to rely on the long-term memory of participants. Some may offer the critical observation that self-monitoring has the potential to decrease the undesirable behavior being monitored, but the impact appears fairly small, as prospective diaries consistently produce higher estimates of sensitive and socially undesirable behavior (e.g., unsafe sex, alcohol use) than do retrospective diaries or global estimates (Carney, Tennen, Affleck, del Boca, \& Kranzler, 1998; Corti et al., 1990; Lemmens, Tan, $\&$ Knibbe, 1992). They also come closest to matching objective measures of the behavior when they have been available (e.g., per capita alcohol revenues). 


\section{Conclusion}

As gambling opportunities become more readily available to Canadian citizens, and as governments accrue increasing amounts of gaming revenue, numerous corresponding social, moral, and policy issues emerge as a direct result. There is little doubt that much government gaming revenue is used to fund the creation and maintenance of important social infrastructure. Moreover, gaming revenue can play an important role in reducing government debt. Such benefits of government gaming revenue, however, cannot be evaluated in isolation from potential problems linked to government-sponsored gambling in Canada. In particular, if government-sponsored gambling is to maintain any moral legitimacy, it is crucial to have an understanding of the extent to which government gaming revenue is generated by people who may have serious gambling problems and addictions.

Existing studies suggest that problem gamblers do indeed generate a disproportionate amount of government gaming revenue. Unfortunately, however, it is difficult to gauge the validity of existing studies as reported expenditures do not match actual government and industry revenues. Nonetheless, it would seem clear that provincial governments need to exert greater efforts to prevent problem gambling, to effectively treat gambling addiction, and to minimize the amount of gambling revenue that comes from problem gamblers.

It is our concluding recommendation that future studies of problem gambling expenditures and revenues employ the prospective diary method outlined in the present article. The prospective diary method has clear potential to transcend the ambiguity associated with expenditure questions and memory fallibility. If executed properly, such an approach could generate highly valid data about problem gamblers' net expenditures as well as the proportion of government gaming revenues generated by problem gambling Canadians. Such valid expenditure and revenue estimates will be crucial in working toward assuring and maintaining an ethos of responsible gambling in Canadian society.

\section{References}

Abbott, M. W., \& Volberg, R. A. (1996). The New Zealand National Survey of problem and pathological gambling, Journal of Gambling Studies, 12, 143-160.

Abbott, M. W., \& Volberg, R. A. (2000). Taking the pulse on gambling and problem gambling in New Zealand: A report on phase ONE of the 1999 National Prevalence Survey. New Zealand: Department of Internal Affairs, Government of New Zealand.

Addictions Foundation of Manitoba. (2002). Gambling involvement and problem gambling in Manitoba. Winnipeg, MB: Addictions Foundation of Manitoba.

American Psychiatric Association (APA). (1994). Diagnostic and statistical manual of mental disorders-(4th ed. (DSM-IV). Washington, DC: APA.

Azmier, J. (2000). Canadian gambling behaviour and attitudes: Main report. Calgary, Alberta: Canada West Foundation. 
Azmier, J. (2001). Gambling in Canada 2001: An overview. Calgary, Alberta: Canada West Foundation.

Azmier, J., Kelley, R., \& Todosichuk, P. (2001). Triumph, tragedy or trade-off? Considering the Impact of Gambling. Calgary, Alberta: Canada West Foundation.

Baseline Marketing Research. (1996). Final report: 1996 prevalence study on problem gambling in Nova Scotia. Prepared for Nova Scotia Department of Health. Halifax, NS: Baseline Marketing Research.

Blaszczynski, A. (2003). Harm minimization strategies in gambling: An overview of international initiatives \& interventions. Prepared on behalf of the Australian Gaming Council. Sydney, Australia: A. Blaszczynski.

Blaszczynski, A., Dumlao, V., \& Lange, M. (1997). How much do you spend gambling? Ambiguities in survey questionnaire items. Journal of Gambling Studies, 13, 237-252.

Carney, M. A., Tennen, H., Affleck, G., del Boca, F. K., \& Kranzler, H. R. (1998). Levels and patterns of alcohol consumption using timeline follow-back, daily diaries and real-time electronic interviews. Journal of Studies on Alcohol, 59, 447-454.

Corti, B., Binns, C. W., Howat, P. A., Blaze-Temple, D., \& Lo, S. K. (1990). Comparison of 7-day retrospective and prospective alcohol consumption diaries in a female population in Perth, Western Australia: Methodological issues. British Journal of Addiction, 85(3), 379-388.

Doiron, J., \& Nicki, R. (1999). The prevalence of problem gambling in Prince Edward Island. Prepared for the Prince Edward Island Department of Health and Social Service. Prince Edward Island.

Ferris, J., \& Wynne, H. (2001). The Canadian Problem Gambling Index Final Report. Submitted to the Canadian Centre on Substance Abuse. Ottawa, Ontario: CCSA.

Gerstein, D., Murphy, S., Toce, M., Hoffmann, J., Palmer, A., Johnson, R., Larison, C., Chuchro, L., Bard, A., Engelman, L., Hill, M. A., Buie, T., Volberg, R., Harwood, H., Tucker, A., Christiansen, E., Cummings, W., \& Sinclair, S. (1999). Gambling impact and behavior study: Report to the National Gambling Impact Study Commission. Chicago: National Opinion Research Center.

Ipsos-Reid \& Gemini Research. (2003). British Columbia Problem Gambling Prevalence Study. Prepared for the Ministry of Public Safety and Solicitor General, British Columbia. British Columbia: Ipsos-Reid \& Gemini Research.

Ladouceur, R. Bouchard, C., Rheaume, N., Jacques, C., Ferland, F., Leblond, J., \& Walker, M. (2000). Is the SOGS an accurate measure of pathological gambling among children, adolescents and adults? Journal of Gambling Studies, 16, 1-24.

Ladouceur, R., Jacques, C., Ferland, F., \& Giroux, I. (1999). Prevalence of problem gambling: A replication study 7 years later. Canadian Journal of Psychiatry, 44, 802-804.

Lemmens, P., Tan, E. S., \& Knibbe, R. A. (1992). Measuring quantity and frequency of drinking in a general population survey: A comparison of five indices. Journal of Studies on Alcohol, 53, 476-486.

Lesieur, H. R. (1998). Costs and treatment of pathological gambling. Annals of the American Academy of Political and Social Science, 556, 153-171.

Lesieur, H. R., \& Blume, S. B. (1987). The South Oaks Gambling Screen (SOGS): A new instrument for the identification of pathological gamblers. American Journal of Psychiatry, 144, 11841188.

Lesieur, H. R., \& Blume, S. B. (1993). Revising the South Oaks Gambling Screen in different settings. Journal of Gambling Studies, 9(3), 213-223.

National Research Council. (1999). Pathological gambling: A critical review. Committee on the Social and Economic Impact of Pathological Gambling, Committee on Law and Justice, Commission on Behavioral and Social Sciences and Education, and the National Research Council. Washington, DC: National Academy Press.

New Brunswick Department of Health \& Wellness \& Focal Research. (2001). 2001 Survey of gambling and problem gambling in New Brunswick. Halifax, Nova Scotia: Focal Research.

Nowatzki, N., \& Williams, R. J. (2002). Casino self-exclusion programs: A review of the issues. International Gambling Studies, 2, 3-26.

Productivity Commission. (1999). Australia's gambling industries, Report No. 10. Canberra, Australia: AusInfo.

Quinn, F. L. (2001). First do no harm: What could be done by casinos to limit pathological gambling. Managerial and Decision Economics, 22, 133-142. 
Ruehlman, L. S. (2001). Development of the gambling practices scale. Paper presented at the 15th National Council on Problem Gambling Conference. June 21-23, 2001. Seattle, Washington.

Schwarz, N. (1999). Self-reports. How the questions shape the answers. American Psychologist, 2, 93-105.

Shaffer, H. J., Hall, M. N., \& Vander Bilt, J. (1997). Estimating the prevalence of disordered gambling behavior in the United States and Canada: A Meta-analysis. Cambridge: Harvard Medical School Division of Addictions.

Smith, G. J., \& Wynne, H. J. 2002. Measuring gambling and problem gambling in Alberta using the Canadian Problem Gambling Index. Prepared for the Alberta Gaming Research Institute. Edmonton, AB: G. J. Smith and H Wynne.

Sobell, L. C., \& Sobell, M. B. (1996). Alcohol timeline followback (TLFB) users' manual. Toronto: Addiction Research Foundation.

Statistics Canada. (2003). Fact-sheet on gambling. Perspectives on Labour and Income, 4(4), 1-5.

Toneatto, T. (1999). Cognitive psychopathology of problem gambling. Substance Use \& Misuse, 34, $1593-1604$.

Toneatto, T., Blitz-Miller, T., Calderwood, K., Dragonetti, R. and Tsanos, A. (1997). Cognitive distortions in heavy gambling. Journal of Gambling Studies, 13, 253-267.

Tourangeau, R. (2000). Remembering what happened: Memory errors and survey reports. In A. A. Stone \& J. S. Turkkan (Eds.), The science of self-report: Implications for research and practice (pp. 29-47). Mahwah, NJ: Erlbaum.

Wiebe, J., Single, E., \& Falkowski-Ham, A. (2001). Measuring gambling and problem gambling in Ontario. Prepared for the Canadian Centre on Substance Abuse \& Responsible Gambling Council (Ontario). Ottawa, Ontario: CCSA.

Wynne, H. J. (2002). Gambling and problem gambling in Saskatchewan. Prepared for the Canadian Centre on Substance Abuse. Ottawa, Ontario: CCSA.

Wynne, H. J., \& Anielski, M. (2000). The Whistler symposium report: The first international symposium on the economic and social impact of gambling. Whistler, British Columbia: The Symposium.

ROBERT J. WILLIAMS, PhD, is an associate professor in the School of Health Sciences, University of Lethbridge, Lethbridge, Alberta, Canada, and the Lethbridge Coordinator for the Alberta Gaming Research Institute. He has published in the areas of seasonal affective disorder, fetal alcohol syndrome, adolescent addictions, and problem gambling. His current research focuses on gambling prevention, Internet gambling, gambling by the elderly, and an investigation into the proportion of gaming revenue derived from problem gamblers.

ROBERT T. WOOD, PhD, is an assistant professor in the Department of Sociology at the University of Lethbridge. He maintains general research interests in a range of areas that include the sociology of youth, criminological theory, and the socio-cultural aspects of gambling. His current research program, however, focuses on several understudied gambling issues, including the characteristics of Internet gamblers, the proportion of revenue that governments derive from problem gamblers, the causes of problem gambling behavior, and the prevention of gambling among adolescents. 